\title{
DESVENDANDO O MITO DA BELEZA: A FALA MÍTICA COMO UMA VIOLÊNCIA SIMBÓLICA DE GÊNERO NA REPRESENTAÇÃO PUBLICITÁRIA DA MULHER
}

Beatriz Molari $^{1}$

Resumo: este artigo tem como objetivo abordar através da perspectiva semiológica de Roland Barthes a manifestação do mito da beleza nas imagens publicitárias da empresa Alezzia Móveis que foram alvo de denúncias pelo público e motivou a abertura de uma ação pelo CONAR (Conselho Nacional de Autorregulamentação Publicitária). O aporte teórico se concentra na fundamentação do mito da beleza desenvolvida pela autora Naomi Wolf, qual demonstra as aplicações da ideologia da beleza como uma coerção social imposta à imagem da mulher. Por esta característica agressiva, o mito da beleza exerce uma forma de violência simbólica, afirmação fundamentada em Pierre Bourdieu. A perspectiva da ideologia da beleza como um mito é baseada nas contribuições de Roland Barthes acerca dos estudos do mito na imagem. As análises de imagens publicitárias confirmaram a fala mítica como uma violência simbólica imposta à imagem da mulher representada na mídia publicitária.

Palavras-chave: Mito da Beleza. Violência simbólica de gênero. Mito. Publicidade.

Abstract: this article aims to approach through the semiological perspective of Roland Barthes the manifestation of the myth of beauty in the publicity images of the company Alezzia Móveis that were the object of denunciations by the public and motivated the opening of an action by CONAR (National Council for SelfRegulatory Advertising). The theoretical contribution focuses on the foundation of the myth of beauty developed by the author Naomi Wolf, which demonstrates the applications of the ideology of beauty as a social coercion imposed on the image of women. By this aggressive

\footnotetext{
${ }^{1}$ Mestranda pelo Programa de Pós-graduação em Comunicação e Imagem e bacharela em Comunicação Social, ambos pela Universidade Estadual de Londrina.
} 
characteristic, the myth of beauty exerts a form of symbolic violence, affirmation based on Pierre Bourdieu. The perspective of the ideology of beauty as a myth is based on the contributions of Roland Barthes on the studies of the myth in the image. The analysis of advertising images confirmed the mythical speech as a symbolic violence imposed on the image of the woman represented in the advertising media.

Key-words: Myth of Beauty. Gender Symbolic Violence. Myth. Advertising.

\section{Introdução}

A história de um grupo é construída pela sua atuação em sociedade ao longo dos tempos. O espaço ocupado pela mulher no meio social sempre foi debatido; principalmente nas sociedades que se desenvolveram sobre as raízes do patriarcalismo, como é o caso do Brasil. Durante séculos a mulher foi vista como um ser humano inferior e submisso ao homem. Suas habilidades eram ignoradas e sua atuação reprimida pelo temor de que a voz da mulher prejudicasse a lógica de dominação masculina. Para manter submissas àquelas que lutavam por mais espaço na sociedade, mitos foram criados $\mathrm{e}$ associados à mulher, sendo o mito da beleza o mais agressivo por atingir a mulher externamente, interferindo na sua aparência física e carreira profissional; e internamente, afetando o seu psicológico com a constante cobrança sobre a sua imagem.

Promovendo um diálogo entre Naomi Wolf, autora de obras que abordam o mito da beleza; e Pierre Bourdieu, sociólogo que se dedicou aos estudos sobre a violência simbólica de gênero, este trabalho tem como objetivo analisar por meio das contribuições semiológicas de Roland Barthes a aplicação do mito da beleza nas imagens de uma campanha publicitária desenvolvida por uma empresa de móveis julgada pelo Conar (Conselho Nacional de Autorregulamentação Publicitária). Através deste estudo será possível investigar a fala mítica empregada pela empresa nas imagens e qual é a representação da mulher transmitida pela publicidade brasileira.

\section{O mito da beleza como uma violência} simbólica de gênero 
Para compreender o que é o mito da beleza é necessário conhecer um pouco sobre o movimento feminista. A história do feminismo é dividida por ondas, cada uma possuía um foco para direcionar as reivindicações, mas todas estão conectadas pela busca de equidade de direitos entre homens e mulheres nos âmbitos sociais. A primeira onda do feminismo teve início no século XX nos Estados Unidos e ficou conhecida como sufragismo. As reivindicações baseavam-se na conquista de direitos políticos para as mulheres, como o voto e a maior participação na esfera pública e melhoria nas oportunidades de estudo oferecidas para as mulheres na época. $\mathrm{O}$ sufragismo se espalhou pelo mundo e teve importantes atuações em vários países. A expansão do movimento fez com que o mesmo fosse fortemente combatido, sendo motivo de prisões das mulheres que atuaram em prol do movimento (ALVES; PITANGUY, 2005). Um fato marcou a luta das sufragistas: a morte de Emily Davison no Derby de Epsom, na Grã-Bretanha, em 4 de junho de 1913. O ato foi uma tentativa de pregar um cartaz sufragista no cavalo do rei Jorge $\mathrm{V}$ para chamar a atenção da sociedade para o movimento (PINTO, 2010). O falecimento de Davison levou
68

seis mil mulheres a marchar pelas ruas de Londres pedindo o direito ao voto.

$$
\text { Este fato motivou }
$$

acontecimentos pontuais em vários países, provocando o desenvolvimento da segunda onda do movimento feminista em 1960, qual teve como foco as desigualdades sociais. Para Pinto, neste momento o feminismo se mostrou um movimento libertário, que ampliava a noção de espaço na sociedade da mulher para o contexto do relacionamento entre homens e mulheres, reivindicando que esta tenha liberdade e autonomia sobre sua vida e seu corpo (PINTO, 2010). Esta fase questionou a domesticidade, mito que pregava satisfação da mulher com a função única de cuidadora dos filhos e do lar. Este mito foi fruto da visão patriarcal que propagava a ideia de que a mulher seria submissa ao homem e, portanto, deve a este toda a sua dedicação, mesmo que para isto necessite abdicar de seus objetivos e aspirações. Combatendo esta doutrina, a segunda onda do feminismo reivindicou o direito da mulher a ter uma carreira profissional e suas habilidades como ser humano reconhecidas pela sociedade. Atribui-se ao momento de transição entre a segunda e terceira onda do movimento feminista as primeiras 
articulações que integravam o pensamento feminista com as discussões sobre etnia, sexualidade e classe. Esta ampliação do feminismo foi reivindicada pelas negras e lésbicas que não se sentiam representadas pelo discurso feminista da época. Estas reivindicações permaneceram na onda seguinte, somando ao foco de combate as coerções sociais sobre o corpo da mulher e as cobranças motivadas pela ideologia da beleza. Neste ponto, a criação do mito da beleza está relacionada com os avanços do movimento feminista. Segundo Wolf, a ideologia da beleza foi desenvolvida com o objetivo de manter uma coerção social sobre as mulheres que se tornaram relativamente incontroláveis pelas conquistas do movimento feminista (WOLF, 1992). Para a autora, "ela [ideologia da beleza] se fortaleceu para assumir a função de coerção social que os mitos da maternidade, domesticidade, castidade e passividade não conseguem mais realizar" (WOLF, 1992, p. 13). Temendo a total liberdade das mulheres, novas coerções sociais foram criadas para que a atuação da mesma como agente de mudança social fosse prejudicada.

Sobre esta questão, Lipovetsky afirma que, na medida em que
[...] as antigas ideologias domésticas, sexuais, religiosas perdem sua capacidade de controlar socialmente as mulheres, as injunções da beleza constituíram o último meio de recompor a hierarquia tradicional dos sexos, de "recolocar as mulheres em seu lugar", de reinstalá-las em uma condição de seres que existem mais por seu parecer que por seu "fazer" social. Alquebrando psicológica e fisicamente as mulheres, fazendo-as perder a confiança em si próprias, absorvendo-as em preocupações estéticonarcísicas, o culto da beleza funcionaria como uma polícia do feminino, uma arma destinada a deter sua progressão social. Sucedendo a prisão doméstica, a prisão estética permitiria reproduzir a subordinação tradicional das mulheres (LIPOVETSKY, 2000, p. 136).

$\mathrm{O}$ autor destaca que o mito da beleza prejudica a atuação da mulher ao impor uma "prisão estética" que engessa a aparência da mulher, sendo mais uma forma de manter a submissão da mesma. O mito da beleza está relacionado com o comportamento feminino, impondo regras à aparência da mulher e por instituir padrões de beleza. As imposições interferem na atuação da 
mulher no seu ambiente de trabalho e também na relação da mesma com outros indivíduos no pelo fato de que a mulher será cobrada a seguir as exigências da ideologia da beleza para ser aceita e ter direito a oportunidades, promovendo um tratamento diferente ao dado aos homens. As desigualdades motivadas pelo mito da beleza atingem a mulher no seu ambiente de trabalho quando a mesma é coagida a investir parte da sua renda em produtos para adequar-se aos padrões exigidos. Essa exigência de beleza imposta às mulheres é condicionada por interferências externas e segue normas que conduzem a aparência e o comportamento daquelas que a ela são subordinadas. Por evidenciar a aparência das mulheres, o mito da beleza reduz as características ao seu exterior, o que, consequentemente, restringe as oportunidades. No âmbito comportamental, o mito da beleza atinge psicologicamente a mulher quando a coloca em estado de vigilância constante. Esta situação é imposta tão agressivamente à mulher que a mesma passa a enxergar como algo natural, o que mostra a influência deste mito.

Ampliando os seus lucros através do mito da beleza, a indústria deste meio envolve mais do que cosméticos e cirurgias plásticas; ela se sustenta na criação da insegurança da mulher com a sua imagem. Wolf afirma que a beleza é um sistema monetário e, como tal, é determinado pela política e economia, ambos sistemas de poder e controle social atualmente (WOLF, 1992). Com uma série de imposições, cobranças estéticas para conseguir ou manter o emprego, inseguranças que freiam a sua atuação e afetam o seu corpo e a mente, a mulher tem a sua atuação como agente de transformação enfraquecida ou mesmo anulada. $\mathrm{O}$ cenário que mais prejudica a mulher é quando a mesma, após ter sua resistência freada tantas vezes, passa a crer que não possui capacidade para mudar o que lhe é forçado. O resultado desta situação imposta é o que Bourdieu chama de impotência aprendida, ou seja, a própria mulher regula a sua atuação acreditando no que terceiros dizem sobre a sua capacidade de ação (BOURDIEU, 2012). Tamanha agressividade do mito da beleza evidencia o seu caráter de violência simbólica de gênero. Segundo Bourdieu, "a violência simbólica é uma violência que se exerce com a cumplicidade tácita dos que a sofrem e também, com frequência, dos que a exercem, na medida em que uns e outros 
são inconscientes de exercê-la ou de sofrê-la" (BOURDIEU, 1997, p. 22).

A violência simbólica é agressiva, pois age com a conivência dos agentes, sendo estes o dominante e o dominado. No entanto, essa cumplicidade nem sempre é racional. A violência simbólica de gênero ocorre dentro de um espaço simbólico que segue a lógica de dominação masculina, esta sendo compreendida como a organização das estruturas sociais em favor dos homens e das instituições que se beneficiam com a submissão feminina. Bourdieu explica que a lógica de dominação é exercida por um princípio simbólico conhecido pelo dominante e o dominado, podendo ser o idioma; estilos de vida diferentes (seja a diferença marcada pelo capital financeiro, cultural ou simbólico; ou por modos distintos de pensamento); ou o que o autor chama de propriedade corporal (a distinção entre os corpos dos indivíduos que integram a sociedade) (BOURDIEU, 2012). No âmbito do gênero, a violência simbólica pode ser percebida em todos os contextos mencionados pelo autor, sendo notada no contexto da propriedade corporal a aplicação do mito da beleza como uma forma de violência simbólica.
$\mathrm{Na}$ lógica de dominação masculina a distinção entre homens e mulheres está baseada na diferença dos gêneros. Para Bourdieu as diferenças entre os órgãos sexuais masculino e feminino “[...] são uma construção social que encontra seu princípio nos princípios de divisão da razão androcêntrica, ela própria fundamentada na divisão dos estatutos sociais atribuídos ao homem e à mulher" (BOURDIEU, 2012, p. 24). Os gêneros carregam conceitos que não estão baseados na biologia, mas que usam desta explicação para embasar a desigualdade social entre homens e mulheres, ou seja, os indivíduos são socializados de formas diferentes de acordo com o sexo que lhe é atribuído. Esta ideia já era defendida por Beauvoir. Para a autora, os indivíduos são divididos em gêneros, mas "não é um corpo, é enquanto corpos submetidos a tabus, a leis, que o sujeito toma consciência de si mesmo e se realiza: é em nome de certos valores que ele se valoriza. E, diga-se mais uma vez, não é a fisiologia que pode criar valores" (BEAUVOIR, 2016, p. 64). As diferenças que baseiam a posição social de cada agente na lógica de dominação são determinadas pela construção das estruturas sociais e seus respectivos 
valores transmitidos. Em uma sociedade patriarcal, que rege seus princípios na crença da inferioridade da mulher em relação ao homem, são criados mecanismos de defesa para possíveis resistências a dominação, como é o caso de atribuir papéis sociais diferentes baseados no gênero. Esta prática fomenta a visão da mulher submissa e fortalece os mitos que prejudicam a construção da mulher como agente social de transformação.

\section{O mito e a imagem para Roland}

\section{Barthes}

O conceito de mito para Barthes foi abordado principalmente em sua obra Mitologias, publicado pela primeira vez em 1957. Sendo uma compilação de artigos escritos a partir de 1950, neste livro Barthes analisa a vida dos franceses daquela época, fazendo uso de uma interpretação similar à representada pelas mídias. Segundo Padillha o autor quis "ilustrar como o mito passa a ser ressignificado ideologicamente na sociedade contemporânea por um discurso que confunde sem cessar Natureza e História" (PADILHA, 2014, p. 10). Barthes explica na introdução do livro que a sua reflexão sobre o mito partiu de uma inquietação com a naturalidade que a mídia e a arte (ou o senso comum, como o autor coloca) tratavam da realidade, qual, segundo ele, era mascarada, distorcida (BARTHES, 1985).

Barthes é enfático ao dizer que “o mito é uma fala" (BARTHES, 1985, p. 199). Como toda fala, o mesmo necessita de condições para ser comunicado. $\mathrm{O}$ autor esclarece que "o mito é um sistema de comunicação, é uma mensagem. Eis por que não poderia ser um objeto, um conceito, ou uma ideia: ele é um modo de significação, uma forma" (BARTHES, 1985, p. 131). Dessa forma, o mito é um sistema semiológico, pois, como Barthes afirma

Pode constatar-se, assim, que no mito existem dois sistemas semiológicos, um deles deslocado em relação ao outro: um sistema linguístico, a língua (ou os modos de representação que lhe são assimilados), a que chamarei linguagem-objeto, porque é a linguagem de que o mito se serve para construir o seu próprio sistema; e o próprio mito, a que chamarei metalinguagem, porque é uma segunda língua, na qual se fala da primeira (BARTHES, 1985, p. 137; grifos do autor). 
A linguagem é formada por significante e significado, e, após o processo de significação, surge o terceiro termo: o signo (BARTHES, 1971). O autor explica que na semiologia o terceiro termo é a associação dos dois primeiros, sendo o terceiro aquele que é de fato "consumido" no meio que é representado (BARTHES, 1985). O autor compreende o mito como o signo, sendo ambos formados por um significante e um significado, sendo que o "plano dos significantes constitui o plano de expressão e o dos significados o plano de conteúdo" (BARTHES, 1971, p. 43; grifos do autor). A junção destes dois planos forma o discurso, este reconhecido como a capacidade discursiva do mito. Sobre isto, Barthes afirma que o discurso

Pode, portanto, não ser oral; pode ser formada por escritas ou por representações: o discurso escrito, assim como a fotografia, o cinema, a reportagem, o esporte, os espetáculos, a publicidade, tudo isto pode servir de esporte, os espetáculos, a publicidade, tudo isto poder servir de suporte à fala mítica. O mito não pode definir-se nem pelo seu objeto, nem pela sua matéria, pois qualquer matéria pode ser arbitrariamente dotada de significação: a flecha apresentada para significar uma provocação é também uma fala (BARTHES, 1985, p. 132).

Uma forma de representação dotada de alta significação é a imagem. Para Barthes a imagem possui uma significação mais imperativa e impõe-se de encontro ao observador (BARTHES, 1985). Nas imagens, o mito é aplicado como uma estratégia que remete a um conceito, sendo este verificado pela associação dos signos visuais e não visuais. Para o estudo das imagens, Cirne explica que

Barthes [...] detecta três níveis para a imagem: 1) o nível informativo, 2) o nível simbólico e 3) o nível da significância. $\mathrm{O}$ primeiro nível resultaria na "mensagem" propriamente dita e seria o nível da comunicação; o segundo implicaria uma abertura psicanalítica, econômica, dramatúrgica e seria o nível da significação; o terceiro revelaria um significante determinado por uma individualidade teórica e seria o nível da semiótica do texto (CIRNE, 1972, p. 28).

Como a imagem possibilita uma análise nestes três níveis, compreende-se 
que a mesma é a linguagem de um objeto (BARTHES, 1985). Compreendendo a formação do mito pela junção de um plano de expressão e outro de conteúdo, as mensagens transmitidas pela imagem podem estar no sistema denotativo, formado por um significante e um significado; ou conotativo, no qual o significante é o resultado da significação de outro sistema (BARTHES, 1971). Barthes explica que a função da denotação nesta mensagem é de persuadir e também de naturalizar a segunda mensagem, assim a mensagem conotativa passa a ser vista como "natural" (BARTHES, 1987), isto pode acobertar significações que promovam a violência simbólica. Quando a imagem trata de uma representação de algo, os signos visuais e textuais que integram a composição da imagem são associados à fala e reforçam as estratégias míticas. $\mathrm{Na}$ representação de agentes sociais, a associação de conceitos à representação pode acarretar ao engessamento do conceito à imagem do agente, como é o caso da mulher representada pela publicidade. Tais conceitos são desenvolvidos com base na compreensão que o social possui sobre a posição da mulher em sociedade. Em uma sociedade que se desenvolveu com o pensamento patriarcal, os conceitos que envolvem a mulher serão aqueles que a representam como submissa ao homem. Quando os mesmos são associados por uma fala mítica à representação da mulher na publicidade, o que ocorre é o fortalecimento dos mitos e a manutenção da lógica de dominação masculina. Dessa forma, pode-se compreender que o uso dos mitos à imagem da mulher contribui para a desigualdade social entre os indivíduos. Os mitos que são frequentemente aplicados à imagem da mulher na publicidade são os que envolvem a domesticidade; maternidade; sexualidade e a objetificação da mesma, os quais integram o conceito de mito da beleza e são analisados a seguir.

\section{Análise da representação da mulher na publicidade e o mito da beleza}

A representação da mulher na mídia sempre foi debatida pela falta de representatividade na imagem transmitida. Estes dois termos possuem o mesmo núcleo, mas significados distintos. A representação de algo ou alguém se refere à exposição de uma ideia concebida por outro, ou seja, é feita por terceiros. A representatividade, por sua vez, envolve a exposição política dos 
interesses de um grupo social. Biroli destaca que a comunicação de uma única forma de vivência disponível para a mulher assemelha-se a um padrão de opressão que organiza as representações da mulher e incentiva maneiras de autoidentificação e de identificação pelos outros (BIROLI, 2013).

A publicidade é o principal meio de associação da imagem da mulher a algum mito. Rocha afirma que "o discurso publicitário fala sobre o mundo, sua ideologia é uma forma básica de controle social, categoriza e ordena o universo. Hierarquiza e classifica produtos e grupos sociais" (ROCHA, 1990, p. 26). A publicidade transmite a ideologia que a ajudará a promover o consumo. Para Baudrillard, todas as atividades sociais acontecem de forma combinada, todas as satisfações são previamente determinadas e " $[\ldots]$ o envolvimento é total, inteiramente climatizado, organizado, culturalizado" (BAUDRILLARD, 2007, p. 19). Portanto, a imagem da mulher é transmitida pela publicidade para manter ao mito da beleza e, consequentemente, a indústria que se favorece da busca por um padrão promovendo produtos $\mathrm{e}$ serviços.
A fala mítica condiciona a imagem da mulher a conceitos que em sua maioria são resultados de coerções sociais. Com uma série de imagens similares no quesito submissão da mulher, as representações da mesma são limitadas. Para Wolf, "através de percepções tão limitadas do universo feminino, as mulheres concluem serem suas opções igualmente limitadas" (WOLF, 1992, p. 64). Sem muitas opções de representação, as mulheres naturalizam os mitos e a concepção de que terceiros podem exercer alguma interferência no seu corpo. A validação dada às imagens transmitidas pela publicidade ocorre por estas terem o caráter de configurações "identitárias", ou seja, são reconhecidas por quem as visualiza, e isto, em uma sociedade patriarcal, limita as representações das mulheres e fortalece os mitos a ela associados (OLIVEIRA; FERNANDES; SILVA, 2009). Esta estratégia vale-se do mito para que o social perca a configuração que a mulher construiu de si e adote as falas que são associadas à sua imagem. Trata-se de um processo de reconfiguração da posição social de um agente, o que pode ser usado como uma estratégia para prejudicar o outro ao promover a representação diferente da 
realidade. Assim, o dominante mantém o seu controle sobre o dominado e este tem a sua atuação repreendida.

$\mathrm{O}$ uso de representações equivocadas pela publicidade foi assunto de uma pesquisa nacional realizada em 2013. Abordando a representação das mulheres na propaganda e na televisão, os resultados mostram que $56 \%$ dos entrevistados não acreditam que as propagandas de televisão mostravam a mulher como ela é na realidade (PATRÍCIA GALVÂO, 2013). Dos entrevistados, $65 \%$ afirmaram que o padrão de beleza nas propagandas na televisão é muito distante da realidade da brasileira. Os dados comprovam a aplicação do mito da beleza nestas mídias e também que o público compreende que estas representações da mulher estão equivocadas. Dados mais recentes mostram que há um biótipo de representação da mulher. Uma pesquisa realizada em 2016 analisou peças publicitárias veiculadas na televisão e publicações em uma rede social, o Facebook. Deste universo, 50\% das representações na televisão seguiam o biótipo da mulher magra e em poses sedutoras; na rede social esse número foi

\footnotetext{
${ }^{2}$ Consciência coletiva que promove ações para
} fortalecer as mulheres e possibilitar a igualdade de
76

de $67 \%$ (HEADS, 2016). Os dados mostram que há um reforço do padrão de beleza considerado como ideal para a mulher; enquanto apenas $5,13 \%$ das 3.038 das inserções expressam alguma forma de empoderamento ${ }^{2}$ das mulheres.

O cenário descrito fica evidente ao investigar o universo de denúncias de propagandas e publicidades analisadas pelo Conar (Conselho Nacional de Autorregulamentação Publicitária) que fazem uso equivocado ou desrespeitoso da representação da mulher. As denúncias partem em sua maioria do público e, caso sejam acatadas pelo Conar, é aberta uma ação para análise. A empresa é reportada e tem o direito de defesa frente a um júri selecionado pelo Conselho. Caso os argumentos da defesa não sejam aceitos pelo júri, a peça publicitária pode ter a sua veiculação sustada.

Um caso de grande repercussão foi movido pelo Conar contra as publicidades da empresa Alezzia Móveis nas redes sociais e no site da mesma. Os denunciantes alegavam que as imagens mostravam os produtos sempre ao lado de uma modelo feminina seminua. Para os denunciantes, havia "clara

sexos, seja no ambiente do trabalho ou no combate a desigualdade social entre homens e mulheres. 
objetificação do corpo da mulher e exposição de nudez de maneira totalmente descontextualizada" (CONAR, 2017). A relatora do caso aceitou as denúncias e propôs a sustação das peças publicitárias. Segundo o relatório da ação, a relatora afirmou que a "divulgação da marca e dos produtos parece seguir uma estratégia de comunicação equivocada e desrespeitosa e realmente é difícil entender qual o objetivo mercadológico de tamanha agressividade" (CONAR, 2017). Ficou evidente que a publicidade veiculada pela marca perdeu o caráter comercial e passou para a instância de violência simbólica. Para a relatora, a "objetivação da mulher é desrespeitosa e seu incentivo demonstra total falta de responsabilidade do anunciante, que desconsidera valores culturais importantes. Além disso, os anúncios são ofensivos e ferem a dignidade feminina" (CONAR, 2017). Este caso demonstra a objetificação da mulher pela publicidade, sendo esta $\mathrm{o}$ ato de reduzir a mulher a um objeto atrativo, sem possuir qualquer conexão com o produto/serviço publicizado pela peça.

As imagens do caso serviram como universo de análise para este trabalho. Mesmo com a sentença aplicada em março de 2017, as imagens ainda estão presentes numa página oficial da marca em uma rede social, mesmo local onde as mesmas foram recolhidas para este estudo. As imagens estão em ordem cronológica e acompanham o texto publicado como legenda pela empresa.

A primeira imagem (Figura 1) foi publicada pela empresa em 7 de janeiro de 2017. A foto mostra uma mulher deitada sobre uma mesa de aço com tampo de madeira. A mulher está trajando um maiô branco de mangas que cobre parte da sua estrutura superior e deixa suas pernas nuas. $\mathrm{O}$ cenário ao fundo sugere ser uma praia, sendo de fácil visualização a areia e parte da água do mar. A legenda da foto faz uma comparação entre a mulher e a mesa ao descrever algo como um "objeto lindo e sexy" e ao final dizer que se refere à mesa. Nota-se que foi proposital a colocação das palavras para sugerir esta comparação. Os elementos presentes na imagem (mulher e mesa) são tratados como objetos, colocação reforçada com a frase inferior, que afirma que a foto é “100\% original de fábrica". 
Figura 1 - Publicação de 7 de janeiro de 2017
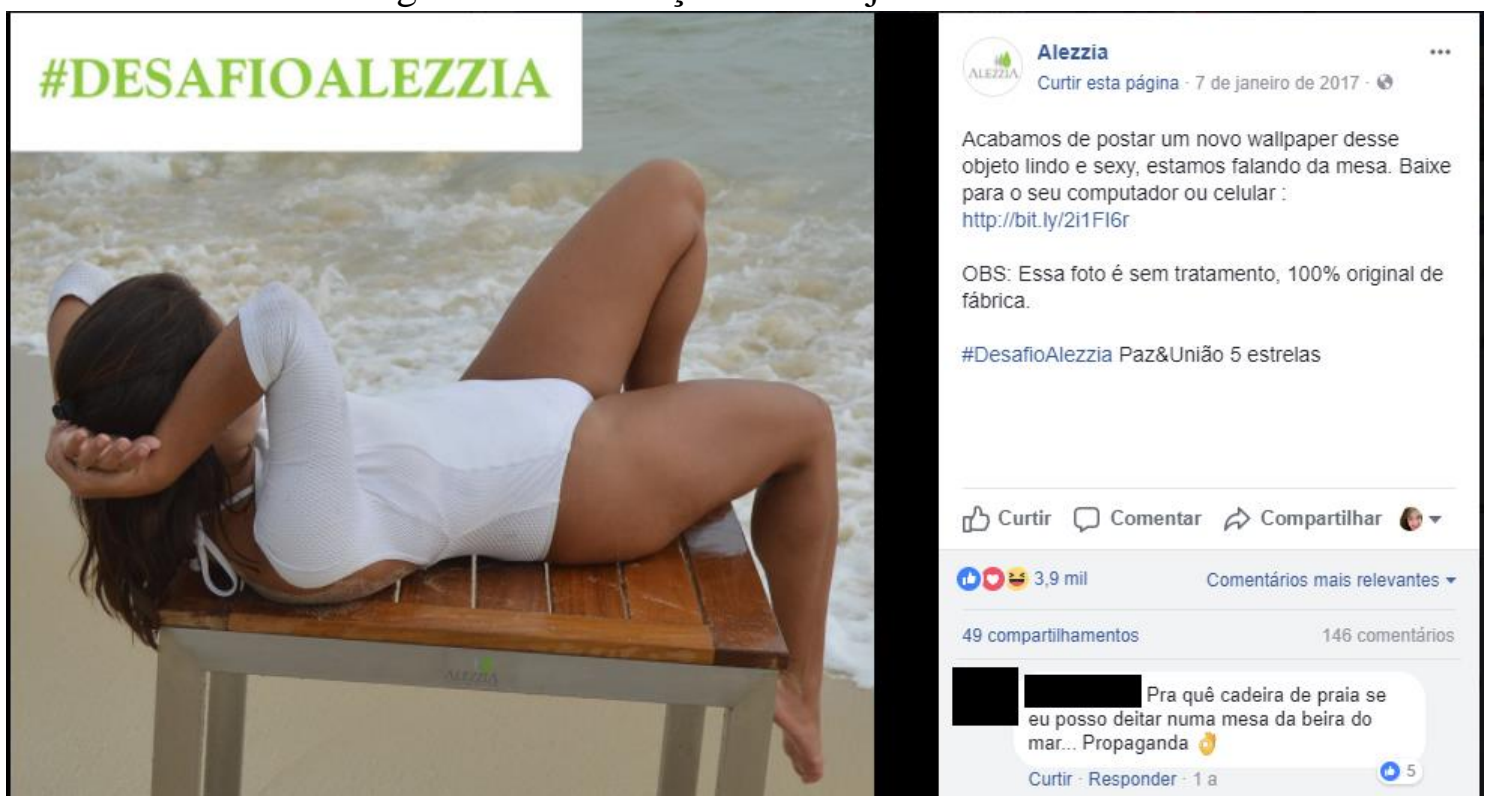

Fonte: Alezzia Móveis, 2017a

A mensagem denotativa sugere a exposição da mesa com o intuito de motivar a compra deste produto. Contudo, a nível conotativo, a mulher foi equiparada ao objeto mesa. Neste, caso a mensagem denotada "mascara" a conotada, sendo uma possível defesa de que a imagem cumpre seu valor de exposição do produto. Nota-se a aplicação do mito da beleza na clara objetificação da mulher. A objetificação da mulher é reconhecida pela empresa e também pelo público, assim como seu caráter agressivo e a intenção da empresa em "agradar" os consumidores que apreciam este tipo de tratamento imposto à mulher.

A segunda imagem (Figura 2) foi publicada em 8 de janeiro de 2017. A mesma mostra uma mulher deitada sobre um muro de cimento e uma cadeira aos seus pés. A mulher está trajando um maiô similar ao usado na Figura 1 e uma bermuda. É possível ver que suas costas e pernas estão nuas. $O$ texto não comunica com a imagem, tornando a representação da mulher totalmente descontextualizada. Assim sendo, o texto passa uma mensagem e a imagem outra. Fica evidente que a imagem foi utilizada como meio de chamar a atenção do público que acessa a página, estes em sua maioria homens. Mais uma vez a empresa usou o mito da objetificação da mulher para a promoção de uma mensagem. Wolf afirma que a beleza é visualizada como um sistema monetário, explorando a mulher e reduzindo a sua 
Periódico do Núcleo de Estudos e Pesquisas sobre Gênero e Direito

Centro de Ciências Jurídicas - Universidade Federal da Paraíba

V. 8 - $\mathrm{N}^{\circ} 01$ - Ano 2019

ISSN | 2179-7137 | http://periodicos.ufpb.br/ojs2/index.php/ged/index

aparência a um corpo pelo qual os um atrativo para as suas publicações e homens se sentirão atraídos (WOLF, sua presença comparada a da cadeira no 1992). Neste caso, a representação da quesito decorativo da publicação.

mulher é utilizada pela empresa como

Figura 2 - Publicação de 8 de janeiro de 2017
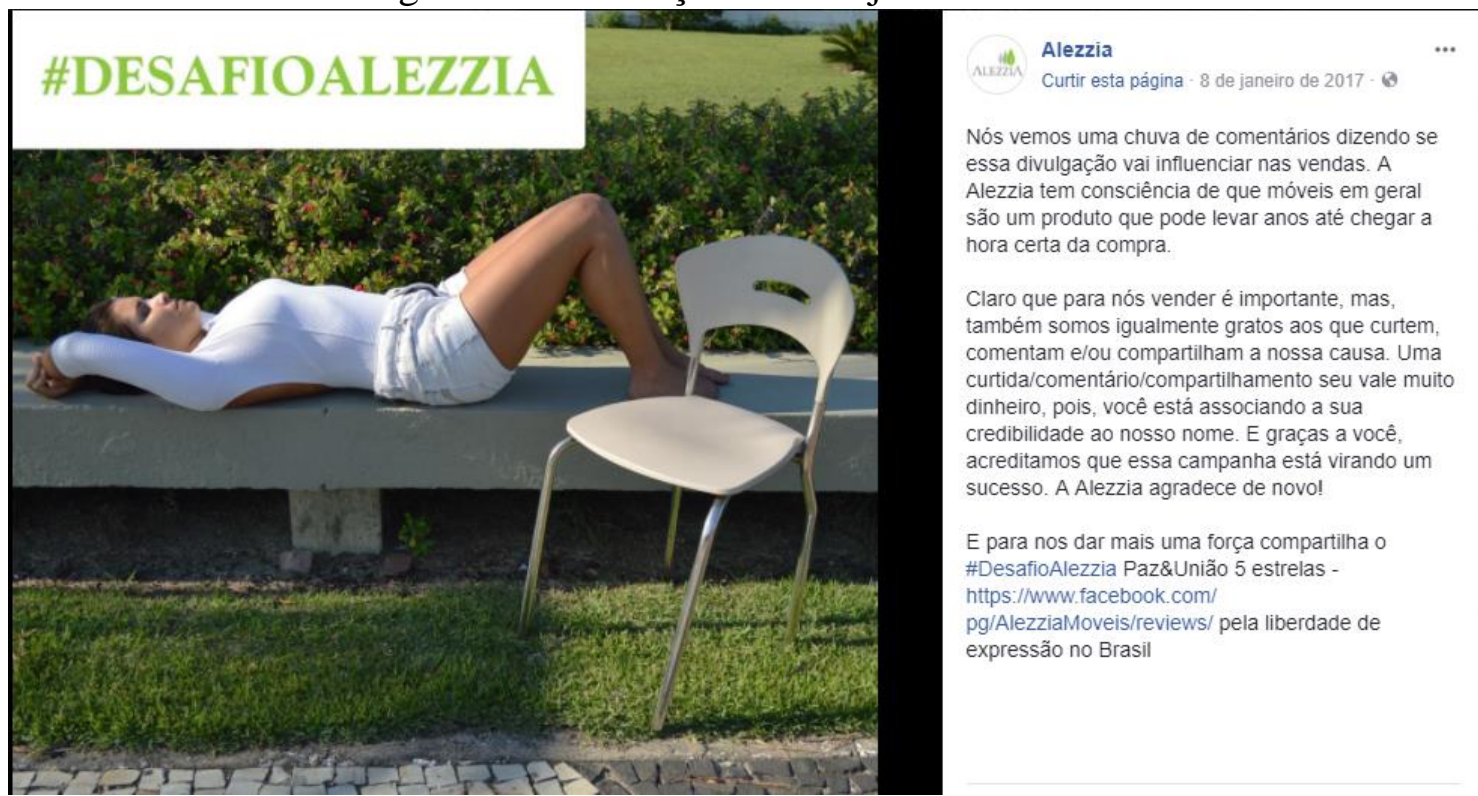

Fonte: Alezzia Móveis, 2017b.

A terceira imagem (Figura 3) foi publicada em 10 de janeiro de 2017 e mostra uma mulher trajando um maiô branco na postura de braços erguidos. Faz parte da composição da imagem uma cadeira de inox e o cenário ao fundo sugere ser um jardim com grama e árvores. A tela da câmera fotográfica está molhada, o que insinua que foi jogada água na direção da mulher e da cadeira. O texto que acompanha a imagem faz referência ao material da cadeira, sendo este reconhecido pelo seu toque gelado ao contato com a pele. $\mathrm{O}$ termo "caloroso" é conotativo, fazendo uma alusão à presença da mulher na imagem, o qual insinua que uma mulher seminua provoca este efeito aos observadores da foto. A representação da mulher nesta imagem é associada à sexualidade. Há uma apropriação do corpo feminino em favor da satisfação sexual do masculino. O corpo seminu é reduzido a um objeto capaz de produzir algum efeito sexual sobre o homem e não como uma forma de expressão da mulher. Para Wolf, a mulher só estará livre do mito da beleza quando puder 
fazer do seu corpo uma forma de expressão própria e seu corpo não mais condicionado ao olhar repressivo e sexualizado do homem (WOLF, 1992).

Figura 3 - Publicação de 10 de janeiro de 2017
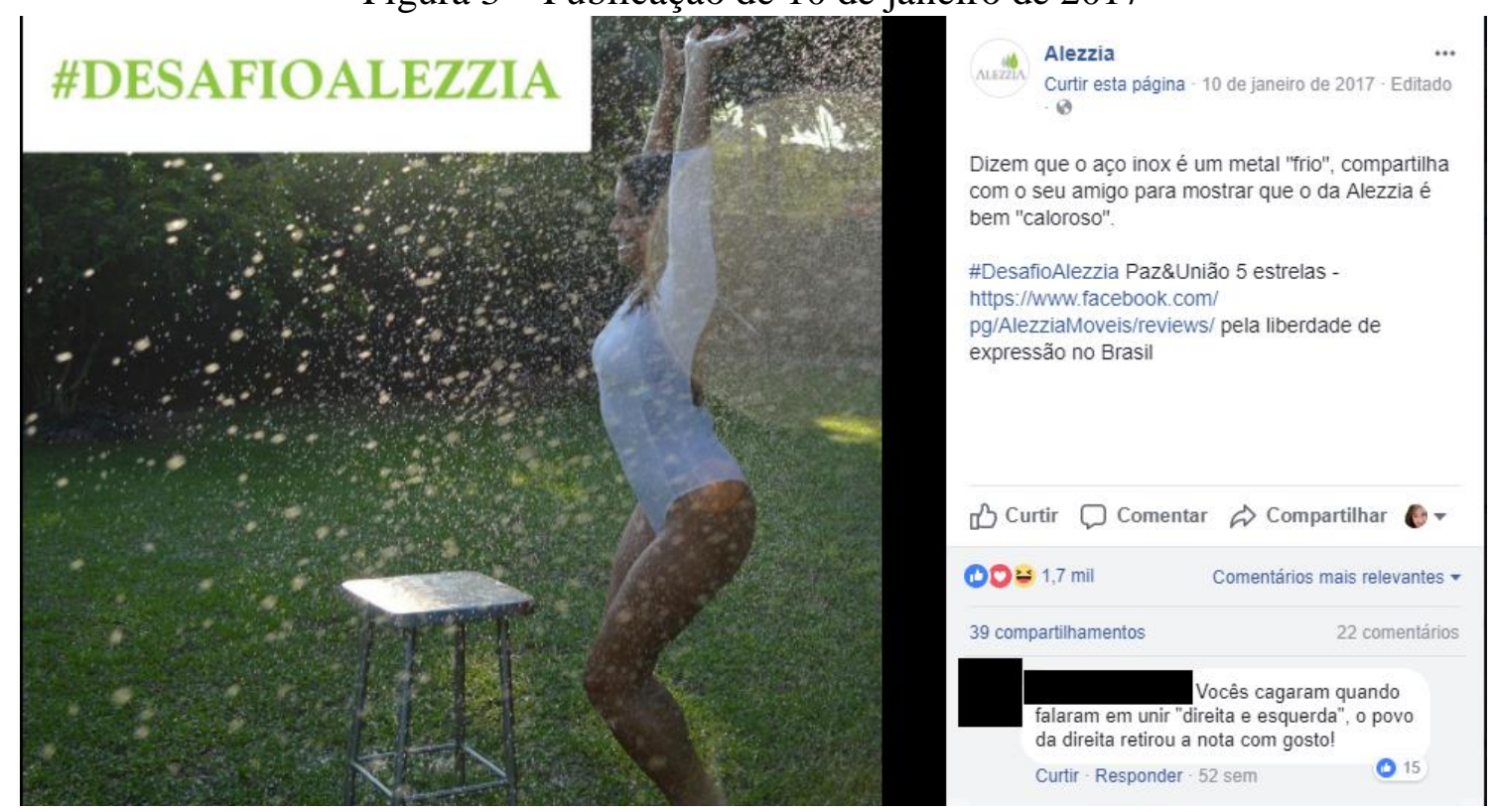

Fonte: Alezzia Móveis, 2017c.

A quarta imagem foi publicada em 15 de abril de 2017 e mostra uma mulher em pé sobre uma mesa de inox com tampo de madeira. A mulher veste apenas um maiô branco e está com as pernas e costas nuas. O cenário é praiano. O texto desta imagem é mais curto e mostra que a empresa fez um wallpaper (imagem usada como elemento decorativo do fundo da tela de um dispositivo eletrônico) da foto para disponibilizar para quem acompanha a página. Uma frase está colocada na parte inferior da imagem e traz uma frase que coloca o corpo da mulher no mesmo patamar que o inox da mesa. A imagem da mulher e do objeto comercializado são tratadas pela empresa como similares, ambas compondo uma imagem a ser dada como agrado aos seus seguidores. A objetificação da mulher é mais uma vez empregada pela empresa em suas publicações. A prática é reconhecida pela empresa ao dizer no final do texto que faz parte das "raízes" da mesma, ou seja, uma forma de comunicação que representa os seus valores. 


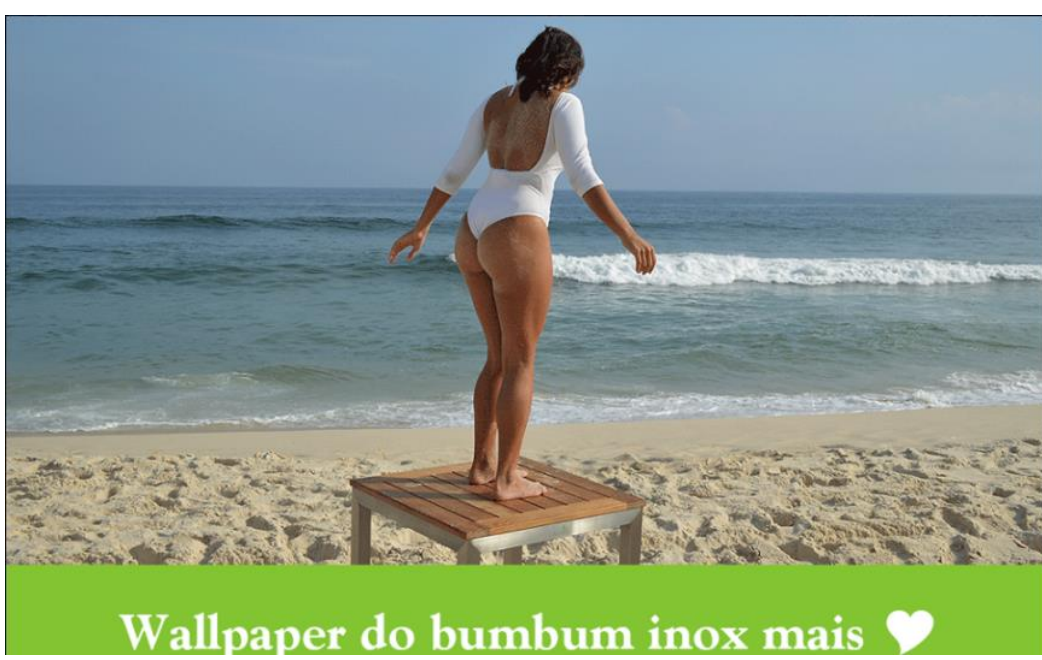

Fonte: Alezzia Móveis, 2017d

As

análises

das

imagensmostraram a aplicação do mito da beleza na representação da mulher. Nas imagens é possível notar que a mulher foi reduzida a sua aparência e seu corpo comparado a um objeto. Os elementos visuais e textuais que compõem a imagem reforçam as intenções da empresa de objetificar, sexualizar e colocar a mulher como algo disposto exclusivamente para o entretenimento masculino, o que está muito distante da publicidade voltada para a comercialização dos produtos. Ao associar a imagem da mulher a um objeto sexual, a empresa reforça o mito da mulher submissa, qual é defendido na visão patriarcal que prega a total soberania do homem sobre a mulher e coloca esta na função de objeto voltado para a satisfação sexual do patriarca. A divulgação de uma campanha publicitária que faça uso de tais mitos é preocupante na medida em que reforça esta visão. Práticas deste tipo fortalecem o machismo e colaboram pela manutenção da violência contra a mulher.

\section{Considerações finais}

A história da mulher em sociedade mostra que a sua imagem sempre esteve associada a um mito. Os avanços do feminismo colaboraram para a conquista de direitos para as mulheres, o que provocou uma reação por parte de instituições que se beneficiaram com a repressão da atuação da mulher em sociedade. Para que a mulher não usufruísse de total liberdade, foi criado o mito da beleza. Este esteve presente na 
vida das mulheres por séculos, sendo reforçado com o avanço das mídias que insistem em reduzir a representação da mulher aos mitos criados pela sociedade. Práticas como as realizadas pela empresa analisada neste estudo mostram que há uma forte violência simbólica de gênero em vigor na sociedade. Por se tratar de conceitos, a transmissão dos mesmos pela mídia regula a imagem recebida

\section{Referências bibliográficas}

ALEZZIA MÓVEIS. Desafio Alezzia. 7 jan. 2017a. Post do Facebook. Disponível em:

https://www.facebook.com/AlezziaMov eis/photos/a.247407785322329.70402.2 25545557508552/1457242601005502/? type $=3 \&$ theater $>$ Acesso em: $15 \mathrm{dez}$. 2018.

Desafio Alezzia. 7 jan. 2017b. Post do Facebook. Disponível em: < https://www.facebook.com/AlezziaMov eis/photos/a.247407785322329/145837

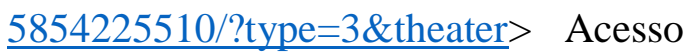
em: 15 dez. 2018.

Desafio Alezzia. 7 jan. 2017c. Post do Facebook. Disponível em: < https://www.facebook.com/AlezziaMov pelo social e, consequentemente, compromete a resistência. Diante de tanta agressividade, resta à mulher duas opções: aceitar as percepções limitadas que lhe são apresentadas; ou iniciar um processo de reapropriação da sua própria identidade, construindo uma nova representação de si que não esteja contaminada por mitos repressores.

eis/photos/a.247407785322329.70402.2 25545557508552/1460030837393345/? type $=3 \&$ theater $>$ Acesso em: $15 \mathrm{dez}$. 2018. Wallpaper do bumbum inox mais do Brasil. 7 jan. 2017d. Post do Facebook. Disponível em: < https://www.facebook.com/AlezziaMov eis/photos/a.247407785322329.70402.2 25545557508552/1569972123065882/? type $=3 \&$ theater $>$ Acesso em: $15 \mathrm{dez}$. 2018.

ALVES, Branca Moreira. PITANGUY, Jacqueline. O que é feminismo. São Paulo: Abril Cultural/Brasiliense, 2005.

BARTHES, Roland. Elementos de semiologia. São Paulo: Editora Cultrix, 1971. 
Mitologias. 6 ed. São Paulo:

Difusão Editorial, 1985.

A mensagem publicitária. In:

BARTHES Roland, A aventura semiológica. Lisboa: Edições 70, 1987.

p. 165-169.

BAUDRILLARD, Jean. A sociedade do consumo. Lisboa: Edições 70, 2007.

BEAUVOIR, Simone de. O segundo sexo: fatos e mitos. 3 ed. Rio de Janeiro: Nova Fronteira, 2016.

BIROLI, Flávia. Autonomia e desigualdades de gênero: contribuição do feminismo para uma crítica democrática. Vinhedo: Editora Horizonte, 2013.

BOURDIEU, Pierre. Sobre a televisão. Rio de Janeiro: Jorge Zahar Ed., 1997.

\section{A dominação masculina. 11}

ed. Rio de Janeiro: Bertrand Brasil, 2012.

CIRNE, Moacy da Costa. Para ler os quadrinhos: da narrativa cinematográfica à narrativa quadrinizada. Petrópolis: Vozes, 1972.
CONAR. Allezia Móveis. 2017.

Disponível em:

http://www.conar.org.br/processos/detc aso.php?id=4537 >. Acesso em: 10 jan. 2018.

HEADS. Todxs por elas. 2016. Disponível em:

http://www.heads.com.br/estudos/36/to dxs-por-elas >. Acesso em: 10 jan. 2018.

LIPOVETSKY, Gilles. A terceira mulher: permanência e revolução do feminismo. São Paulo: Companhia das Letras, 2000.

OLIVEIRA, Ana Cláudia de; FERNANDES, Cíntia Sanmartin; SILVA, Simone Bueno da. A construção do corpo feminino na mídia semanal. Comunicação, Mídia e Consumo, São Paulo, v. 6, n. 17, p.1136, nov. 2009. Quadrimestral.

PADILLHA, Conrado Valle de Queiroz. $O$ conceito de mito na obra de Roland

Barthes: desdobramentos e atualidade. 2014. 70 f. Dissertação (Mestrado em Comunicação) - Pontifícia Universidade Católica de São Paulo, São Paulo: 2014. Disponível em: 
https://tede2.pucsp.br/handle/handle/46

43 > Acesso em: 9 jan. 2018.

PATRÍCIA GALVÃO, Instituto.

Pesquisa Representações das

mulheres nas propagandas de TV.

2013. Disponível em: <

http://agenciapatriciagalvao.org.br/mulh

er-e-midia/pautas-midia/pesquisa-

revela-que-maioria-nao-ve-as-mulheres-

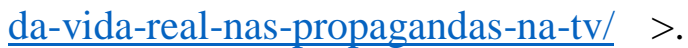

Acesso em: 10 jan. 2018.

PINTO, Céli Regina Jardim. Feminismo, história e poder. Revista de Sociologia e

Política, Curitiba, v. 18, n. 36, p.15-23, jun. 2010. Disponível em: < http://www.scielo.br/pdf/rsocp/v18n36/ 03.pdf>. Acesso em: 18 mar. 2019.

ROCHA, Everardo P. Guimarães. Magia e Capitalismo: um estudo antropológico da publicidade. 2 ed. São Paulo: Brasiliense, 1990.

WOLF, Naomi. O mito da beleza: como as imagens de beleza são usadas contra as mulheres. São Paulo: Rocco, 1992 